\title{
Use of platelet glycoprotein IIb/IIIa inhibitors in diabetics undergoing PCI for non-ST-segment elevation acute coronary syndromes: impact of clinical status and procedural characteristics
}

\author{
Timm Bauer • Helge Möllmann · Franz Weidinger • Uwe Zeymer • Ricardo Seabra-Gomes • \\ Franz Eberli • Patrick Serruys • Alec Vahanian · Sigmund Silber · William Wijns • \\ Matthias Hochadel · Holger M. Nef • Christian W. Hamm · Jean Marco • Anselm K. Gitt
}

Received: 14 October 2009/ Accepted: 5 February 2010/Published online: 26 February 2010

(c) The Author(s) 2010. This article is published with open access at Springerlink.com

\begin{abstract}
Background The most recent ESC guidelines for percutaneous coronary intervention (PCI) recommend the use of glycoprotein IIb/IIIa inhibitors (GPI) in high risk patients with non-ST-segment elevation acute coronary syndromes (NSTE-ACS), particularly in diabetics. Little is known about the adherence to these guidelines within Europe.

Methods and results Between May 2005 and April 2008 a total of 47,407 consecutive patients undergoing PCI were prospectively enrolled into the PCI-Registry of the Euro Heart Survey Programme. In the present analysis we examined the use of GPI in 2,922 diabetics who underwent
\end{abstract}

ESC Board Committee for the Euro Heart Survey Programme 20062008: Anselm K. Gitt (Chairperson) (Germany), Hector Bueno (Spain), Nicolas Danchin (France), Kevin Fox (UK), Peter Kearney (Ireland), Aldo Maggioni (Italy), Keith McGregor (France), Gregorsz Opolski (Poland), Ricardo Seabra-Gomes (Portugal), Franz

Weidinger (Austria).

T. Bauer $(\bowtie) \cdot$ H. Möllmann · H. M. Nef · C. W. Hamm

Kerckhoff-Klinik, Kardiologie, Benekestr. 2-8,

61231 Bad Nauheim, Germany

e-mail: Bauer-Timm@gmx.de

F. Weidinger

Krankenhaus Rudolfstiftung, Vienna, Austria

U. Zeymer · M. Hochadel · A. K. Gitt

Herzzentrum Ludwigshafen, Institut für Herzinfarktforschung Ludwigshafen an der Universität Heidelberg, Ludwigshafen,

Germany

R. Seabra-Gomes

Instituto do Coraçăo, Lisbon, Portugal

F. Eberli

Stadtspital Triemli, Zurich, Switzerland
PCI for NSTE-ACS. In this high risk population only $22.2 \%$ received a GPI; $8.9 \%$ upstream and $13.4 \%$ during PCI. The strategy of the individual institution had a major impact on the usage of GPI. In the multiple regression analysis clinical instability and complex lesion characteristics were strong independent determinants for the use of GPI, whereas renal insufficiency was negatively associated with its use. After adjustment for confounding variables no significant differences in hospital mortality could be observed between the cohorts, but a significantly higher rate of non-fatal postprocedural myocardial infarction was observed among patients receiving GPI upstream.

Conclusions Despite the recommendation for its use in the current ESC guidelines, only a minority of the diabetics in Europe undergoing PCI for NSTE-ACS received a GPI. The use of GPI was mainly triggered by high-risk interventional scenarios.

\section{P. Serruys}

Thoraxcenter, Erasmus MC, Rotterdam, The Netherlands

\author{
A. Vahanian \\ Bichat Hospital, Paris, France
}

S. Silber

Kardiologische Gemeinschaftspraxis und Praxisklinik, Munich,

Germany

W. Wijns

Cardiovascular Center, Aalst, Belgium

J. Marco

Centre Cardiothoracique de Monaco, Monaco Cedex, Monaco 
Keywords Non-ST-segment elevation acute coronary syndrome · Platelet glycoprotein IIb/IIIa inhibitor . Percutaneous coronary intervention - Diabetes mellitus . Clinical practice

\section{Introduction}

Platelet glycoprotein IIb/IIIa inhibitors (GPI) are potent and rapidly acting anti-platelet agents. They block the final common pathway of platelet aggregation and inhibit the bridging between activated platelets [1,2]. Randomized controlled trials investigating the effect of GPI in patients with non-ST-segment elevation acute coronary syndromes (NSTE-ACS) treated with percutaneous coronary intervention (PCI) have revealed a significant risk reduction for death and myocardial infarction at 30 days [3-5]. However, thienopyridines and stents were not commonly used in these trials.

Diabetes mellitus is a major risk factor for the development of coronary artery disease (CAD), and compared with their non-diabetic counterparts, diabetic patients have higher morbidity and mortality in the setting of ST-elevation myocardial infarction and NSTE-ACS [6, 7]. Roffi et al. [8] performed a meta-analysis of diabetics enrolled in large-scale GPI acute coronary syndrome (ACS) trials. Among diabetic patients the use of GPI was associated with a significant mortality reduction, whereas non-diabetic patients had no survival benefit. Furthermore, the risk reduction seemed to be more pronounced in diabetics treated with PCI.

Consequently, the most recent PCI guidelines of the ESC recommend GPI in patients with high risk, particularly patients with elevated troponins, ST-depression, or diabetes and planned or performed PCI [9]. Within the large Euro Heart Survey (EHS) PCI Registry, which enrolled consecutive patients from 2005 until 2008, we evaluated how these guidelines are adhered to in Europe among diabetics undergoing PCI for NSTE-ACS. In addition, a multiple logistic regression analysis was conducted to detect determinants for the use of GPI.

\section{Methods}

The PCI-Registry of the EHS Programme

The PCI-Registry is a prospective, multi-centre, observational study on current practice of unselected patients undergoing elective or emergency PCI. Consecutive patients with ACS or stable CAD were recruited within the period from May 2005 to April 2008. The participating hospitals were located throughout Europe (176 centres in 33 ESC-countries) and included university hospitals, community hospitals, specialist cardiology centres and private hospitals all performing PCI. The mean annual PCI volume of the participating facilities was approximately 1,000.

During the specified period all patients treated with PCI were prospectively registered and followed during their clinical course to document patient characteristics, adjunctive medical treatment, procedural details and in-hospital outcomes.

\section{Study population}

In 10,754 patients with NSTE-ACS, diabetic status and treatment with or without GPI was documented. Among these patients, 2,922 (27.2\%) were diabetics and 7,832 (72.8\%) non-diabetics. This present study is a detailed analysis of the diabetic patients who were divided into three groups: upstream (treatment started before diagnostic angiogram), downstream (started during PCI, but not before PCI) and no GPI.

\section{Data collection}

On admission, data on patient characteristics were recorded, including age, gender, cardiovascular risk factors, concomitant diseases, prior myocardial infarction, prior stroke, prior cardiovascular interventions and chronic medical treatment, as well as data on symptoms and prehospital delay. Data on electrocardiographic findings, biochemical markers, procedural details and adjunctive therapy were documented. At discharge, major cardiovascular, cerebrovascular adverse events, puncture site complications and recommended medical treatment were recorded.

Every participating centre was committed to include every consecutive patient undergoing PCI during selected time periods. If continuous enrollment was not feasible due to high annual numbers of PCI, these centres were asked to recruit consecutive patients from day 1 to 7 of every calendar month during the entire study period. All patients gave written informed consent for processing their anonymous data. Electronic case report forms were used for data entry and transferred via the web to a central database located in the European Heart House, where they were edited for missing data, inconsistencies and outliers. Additional editing of the data as well as the statistical analyses for this publication was performed at the Institut fuer Herzinfarktforschung Ludwigshafen an der Universitaet Heidelberg, Germany. The study was approved by the ethics committees responsible for the participating centres as required by local rules. 


\section{Definitions}

In patients without initial myocardial infarction, clinical signs of ischemia and relevant increases of cardiac biomarkers were defined as postprocedural myocardial infarction. Postprocedural reinfarction was diagnosed if patients had signs of recurrent ischemia and an additional relevant increase of cardiac biomarkers. Bleeding complications were classified as major when the patient had an intracranial bleed or overt clinical bleeding with a drop in hemoglobin of greater than $5 \mathrm{~g} / \mathrm{dl}$. Chronic renal failure was diagnosed by any of the following: serum creatinine $>2 \mathrm{mg} / \mathrm{dl}$ or $200 \mu \mathrm{mol} / \mathrm{l}$ in the past, on dialysis or history of renal transplantation. Major adverse cardiac events (MACE) comprise all deaths and post-procedural myocardial infarctions during hospital stay.

\section{Statistical methods}

Categorical data are presented as absolute numbers and percentages, metrical data as medians with 25 th and 75 th percentiles. The frequencies of categorical variables in two populations were compared between two groups by Pearson $\chi^{2}$ test and by calculating odds-ratios (OR) and $95 \%$ confidence intervals (CI). Continuous and ordinal variables were compared by Mann-Whitney-Wilcoxon test. Descriptive statistics were calculated from the available cases.

The impact of different baseline, angiographic and procedural variables on the use of upstream and downstream GPI treatment was evaluated by marginal logistic regression models and calculating the odds ratios with $95 \%$ confidence intervals using generalized equations with exchangeable working correlation matrix in order to account for clustering by centres. The multivariate analysis regarding the upstream use compared patients receiving GPI before PCI with those treated never or later and included as explanatory variables: age (per 10-year increase), female gender, peripheral vascular disease (PAD), chronic renal failure, non-ST elevation myocardial infarction (NSTEMI), hemodynamic instability on admission (cardiogenic shock or/and resuscitation), chronic medication with acetylsalicylic acid (ASA) and vitamin K antagonist, usage of unfractionated (UFH) or low molecular weight heparin (LMWH) before or during PCI. Concerning the downstream regime the groups receiving GPI during PCI versus no GPI were compared excluding patients on upstream treatment and the following variables were incorporated in the analysis: age (per 10-year increase), chronic renal failure, Western Europe, Mediterranean region, radial access, $>1$ segment treated, type $\mathrm{C}$ lesion, drug-eluting stents (DES), no/slow flow during intervention, acute segment occlusion. These variables were specified by clinical considerations and all of them had a bi-variate association with hospital mortality with $p<0.2$. Furthermore, we evaluated the effect of upstream and downstream GPI treatment on hospital mortality and non-fatal myocardial infarction. Odds ratios for death versus no MACE and non-fatal myocardial infarction versus no MACE were estimated in multinomial logitregression models with adjustment for age (per 10-year increase), hemodynamic instability, acute NSTEMI, threevessel disease, history of chronic renal failure, prior stroke and PAD, downstream treatment also for multi-segment PCI, acute segment occlusion and no/slow flow. The no GPI group with the lowest risk for death and myocardial infarction was defined as reference group.

$P$ values $\leq 0.05$ were considered significant. All $p$ values are results of two-tailed tests and are not adjusted for multiple testing. The analysis was performed with the $\mathrm{SAS}^{\circledR}$ system release 9.1 on a personal computer (SAS Institute, Inc., Cary, NC, USA).

\section{Results}

Patients and baseline characteristics

For the present analysis 2,922 diabetic patients with NSTEACS were examined and stratified into three categories: 259 patients $(8.9 \%)$ receiving upstream, 391 patients (13.4\%) downstream and 2,272 patients (77.8\%) no GPI. Non-diabetics were more frequently treated with GPI. In comparison to diabetics the percentage of upstream $(12.0 \%)$ and downstream $(14.9 \%)$ treatment was significantly higher $(p<0.0001)$. The baseline characteristics of the diabetics patients are shown in Table 1. There was no relevant age difference between the three groups. Women more often received upstream treatment. GPI was less commonly administrated to patients with a history of PAD and chronic renal failure.

\section{GPI in different European regions}

The percentage of diabetic patients receiving upstream treatment was similar across Europe, but downstream treatment was most frequent in Mediterranean countries followed by Central and Western Europe. The numbers of patients from Northern Europe which contributed data are too small to be representative (Fig. 1). Large differences in the utilization of GPI were observed between the participating centres (Fig. 2).

Initial assessment and diagnosis

The majority of diabetics presenting with NSTEMI or cardiogenic shock did not receive a GPI, but in those who 
Table 1 Baseline characteristics

\begin{tabular}{|c|c|c|c|c|c|}
\hline & $\begin{array}{l}\text { No GPI } \\
N=2,272\end{array}$ & $\begin{array}{l}\text { Upstream } \\
N=259\end{array}$ & $\begin{array}{l}P \text { value } \\
\text { (no vs. up) }\end{array}$ & $\begin{array}{l}\text { Downstream } \\
N=391\end{array}$ & $\begin{array}{l}P \text { value } \\
\text { (no vs. down) }\end{array}$ \\
\hline \multicolumn{6}{|l|}{ Demographics } \\
\hline Age (years) & $67.6(59.6-74.9)$ & $68.6(60.4-75.5)$ & ns & $66.9(59.8-73.4)$ & ns \\
\hline Women & $788(34.7 \%)$ & $110(42.5 \%)$ & $<0.05$ & $136(34.8 \%)$ & ns \\
\hline BMI $\left(\mathrm{kg} / \mathrm{m}^{2}\right)$ & $28.4(25.9-31.3)$ & $28.7(25.8-32.9)$ & ns & $28.1(25.8-31.4)$ & $\mathrm{ns}$ \\
\hline \multicolumn{6}{|l|}{ History relevant to CAD } \\
\hline Prior myocardial infarction & $833 / 2,257(36.9 \%)$ & $93 / 249(37.3 \%)$ & ns & $143 / 383(37.3 \%)$ & ns \\
\hline Prior PCI & $641 / 2,256(28.4 \%)$ & $54 / 249(21.7 \%)$ & $<0.05$ & $103 / 383(26.9 \%)$ & ns \\
\hline Prior CABG & $219 / 2,256(9.7 \%)$ & $23 / 249(9.2 \%)$ & ns & $46 / 383(12.0 \%)$ & ns \\
\hline Hx of stroke & $176 / 2,256(7.8 \%)$ & $18 / 249(7.2 \%)$ & ns & $19 / 383(5.0 \%)$ & $\leq 0.05$ \\
\hline Hx of peripheral vascular disease & $278 / 2,256(12.3 \%)$ & $16 / 249(6.4 \%)$ & $<0.01$ & $34 / 383(8.9 \%)$ & 0.05 \\
\hline Hx of chronic renal failure & $217 / 2,256(9.6 \%)$ & $16 / 249(6.4 \%)$ & ns & $21 / 383(5.5 \%)$ & $<0.01$ \\
\hline \multicolumn{6}{|l|}{ Risk factors } \\
\hline Hypertension & $1,880 / 2,263(83.1 \%)$ & $216 / 257(84.0 \%)$ & ns & $321 / 389(82.5 \%)$ & ns \\
\hline HLP & $1,519 / 2,166(70.1 \%)$ & $194 / 246(78.9 \%)$ & $<0.01$ & $275 / 380(72.4 \%)$ & ns \\
\hline Current/former smoker & $1,003 / 2,185(45.9 \%)$ & $101 / 249(40.6 \%)$ & ns & $176 / 376(46.8 \%)$ & ns \\
\hline
\end{tabular}

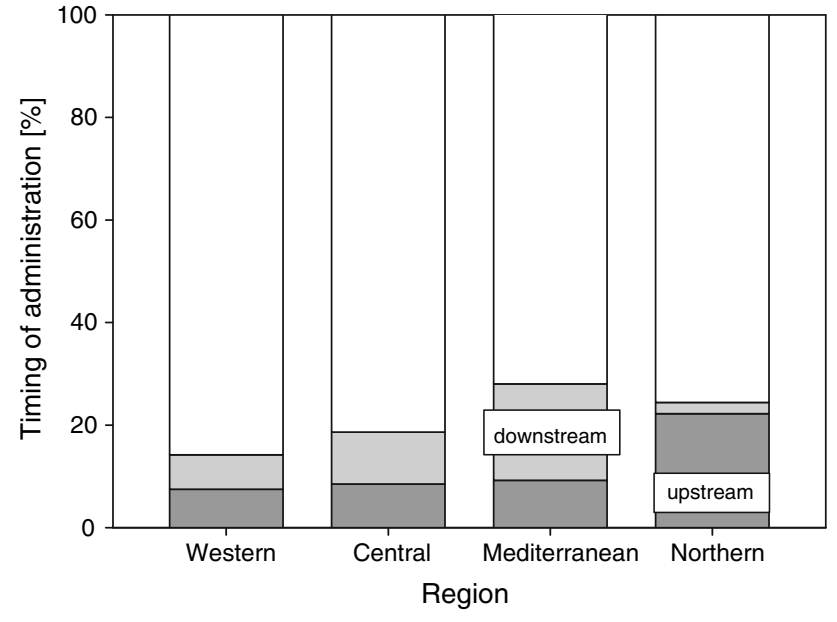

Fig. 1 Use of GP IIb/IIIa inhibitors in different European regions

did, it was given rather upstream than downstream (Table 2).

Angiographic and interventional characteristics

Diabetic patients undergoing PCI of left main stem (LM), bypass grafts and more than one segment more frequently received GPI. Nevertheless, only $34.6 \%$ of patients with PCI of LM, $34.8 \%$ with bypass interventions and $30.9 \%$ with multi-segment PCI were treated with GPI. Lesion characteristics were more complex among patients with downstream treatment.

The stenting rate was higher among patients with GPI. Diabetic patients with DES more often received

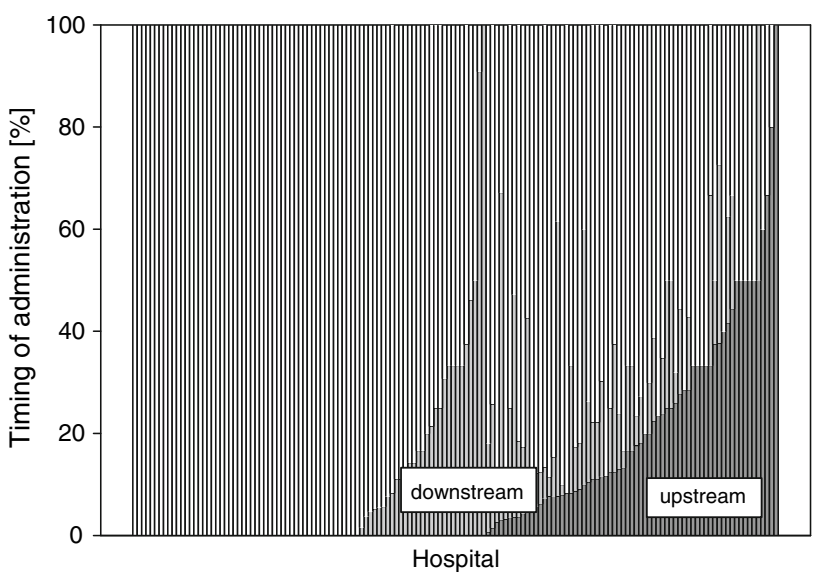

Fig. 2 Use of GP IIb/IIIa inhibitors per centre

downstream treatment. There were no major differences in procedural success among the groups. Downstream administration of GPI was more commonly observed in patients with acute segment closure and no/slow flow (Table 3).

Antithrombotic medication

Diabetics with chronic ASA medication were less frequently treated with GPI. Before and during PCI diabetics with GPI were more likely to receive ASA and LMWH, and less likely to receive UFH. There were no relevant differences in the rate of clopidogrel loading doses (upstream and started in the catheterization laboratory) 
Table 2 Initial assessment and diagnosis

\begin{tabular}{|c|c|c|c|c|c|}
\hline & $\begin{array}{l}\text { No GPI } \\
N=2,272\end{array}$ & $\begin{array}{l}\text { Upstream } \\
N=259\end{array}$ & $\begin{array}{l}P \text { value } \\
\text { (no vs. up) }\end{array}$ & $\begin{array}{l}\text { Downstream } \\
N=391\end{array}$ & $\begin{array}{l}P \text { value } \\
\text { (no vs. down) }\end{array}$ \\
\hline \multicolumn{6}{|l|}{ Diagnosis } \\
\hline NSTEMI & $930(40.9 \%)$ & $171(66.0 \%)$ & $<0.0001$ & $176(45.0 \%)$ & ns \\
\hline Unstable angina & $1342(59.1 \%)$ & $88(34.0 \%)$ & $<0.0001$ & $215(55.0 \%)$ & ns \\
\hline Cardiogenic shock & $26 / 2,269(1.1 \%)$ & $13(5.0 \%)$ & $<0.0001$ & $8 / 390(2.1 \%)$ & ns \\
\hline Resuscitation & $22 / 2,270(1.0 \%)$ & $8(3.1 \%)$ & $<0.01$ & $4 / 390(1.0 \%)$ & ns \\
\hline \multicolumn{6}{|c|}{ Left ventricular function } \\
\hline Reduced $(<50 \%)$ & $740 / 1,897(39.0 \%)$ & 79/196 (40.3\%) & $\mathrm{ns}$ & $114 / 304(37.5 \%)$ & $\mathrm{ns}$ \\
\hline
\end{tabular}

Table 3 Angiographic and interventional characteristics

\begin{tabular}{|c|c|c|c|c|c|}
\hline & $\begin{array}{l}\text { No GPI } \\
N=2,272\end{array}$ & $\begin{array}{l}\text { Upstream } \\
N=259\end{array}$ & $\begin{array}{l}P \text { value } \\
\text { (no vs. up) }\end{array}$ & $\begin{array}{l}\text { Downstream } \\
N=391\end{array}$ & $\begin{array}{l}P \text { value } \\
\text { (no vs. down) }\end{array}$ \\
\hline \multicolumn{6}{|l|}{ Stenosed vessels $(\geq 50 \%)$} \\
\hline Left main stem & $112(4.9 \%)$ & $13(5.0 \%)$ & ns & $25(6.4 \%)$ & ns \\
\hline Multi-vessel disease & $1,559(68.6 \%)$ & $158(61.0 \%)$ & $<0.05$ & $279(71.4 \%)$ & ns \\
\hline \multicolumn{6}{|l|}{ Arterial access } \\
\hline Femoral & $2,008 / 2,271(88.4 \%)$ & $223 / 258(86.4 \%)$ & ns & $332(84.9 \%)$ & $\leq 0.05$ \\
\hline Radial & 244/2,271 (10.7\%) & $34 / 258(13.2 \%)$ & ns & $58(14.8 \%)$ & $<0.05$ \\
\hline \multicolumn{6}{|l|}{ Treated vessels } \\
\hline Left main stem & $51(2.2 \%)$ & $10(3.9 \%)$ & ns & $17(4.3 \%)$ & $\leq 0.05$ \\
\hline Bypass & $60(2.6 \%)$ & $13(5.0 \%)$ & $<0.05$ & $19(4.9 \%)$ & $<0.05$ \\
\hline$>1$ segment & $701(30.9 \%)$ & $105(40.6 \%)$ & ns & $209(53.5 \%)$ & $<0.0001$ \\
\hline \multicolumn{6}{|l|}{ Lesion characteristics } \\
\hline Type C & $701 / 2,272(30.7 \%)$ & $88 / 257(34.2 \%)$ & ns & $164 / 390(42.1 \%)$ & $<0.0001$ \\
\hline Bifurcation & $412 / 2,266(18.2 \%)$ & $50 / 258(19.4 \%)$ & ns & $96 / 390(24.6 \%)$ & $<0.01$ \\
\hline TIMI flow $0-2$ before PCI & $897 / 2,248(39.9 \%)$ & $149 / 258(57.8 \%)$ & $<0.0001$ & $187 / 390(47.9 \%)$ & $<0.01$ \\
\hline \multicolumn{6}{|l|}{ Therapeutic devices } \\
\hline Stent implantation & $2,078(91.5 \%)$ & $246(95.0 \%)$ & 0.05 & $373(95.4 \%)$ & $<0.01$ \\
\hline Bare-metal stent & $1,201 / 2,271(52.9 \%)$ & $134(51.7 \%)$ & ns & $152(38.9 \%)$ & $<0.0001$ \\
\hline Drug-eluting stent & $970 / 2,271(42.7 \%)$ & $135(52.1 \%)$ & $<0.01$ & $261(66.8 \%)$ & $<0.0001$ \\
\hline Balloon pump & $19 / 2,237(0.8 \%)$ & $10 / 258(3.9 \%)$ & $<0.0001$ & $7 / 384(1.8 \%)$ & ns \\
\hline \multicolumn{6}{|l|}{ Procedural details } \\
\hline TIMI 3 flow after PCI & $2,090 / 2,262(92.4 \%)$ & $241 / 258(93.4 \%)$ & ns & $358(91.6 \%)$ & ns \\
\hline$<50 \%$ Stenosis after PCI & $2,129 / 2,265(94.0 \%)$ & $246(95.0 \%)$ & ns & $377 / 390(96.7 \%)$ & $<0.05$ \\
\hline Acute segment closure & $15 / 2,225(0.7 \%)$ & $3 / 253(1.2 \%)$ & ns & $10 / 379(2.6 \%)$ & $<0.001$ \\
\hline No/slow flow & $26 / 2,224(1.2 \%)$ & $3 / 253(1.2 \%)$ & ns & $21 / 379(5.5 \%)$ & $<0.0001$ \\
\hline
\end{tabular}

between the three groups. The rate of 300 and $600 \mathrm{mg}$ doses were also similar (data not shown). Patients treated with upstream GPI more frequently received clopidogrel at discharge (Table 4).

\section{Distribution of the different GPI}

In an upstream treatment regime tirofiban $(n=180$, $69.5 \%$ ) was most often used, followed by eptifibatide $(n=60,23.2 \%) \quad$ and abciximab $(n=23, \quad 8.9 \%)$.
Downstream the use of abciximab $(n=151,38.6 \%)$ increased, the use of tirofiban $(n=147,37.6 \%)$ decreased, whereas the percentage of eptifibatide did not change $(n=93,23.8 \%)$.

Determinants for the upstream use of GPI

After adjustment for confounding variables NSTEMI was an independent determinant for the upstream use of GPI in diabetics. There was a strong tendency towards a higher 
Table 4 Antithrombotic medication

\begin{tabular}{|c|c|c|c|c|c|}
\hline & $\begin{array}{l}\text { No GPI } \\
N=2,272\end{array}$ & $\begin{array}{l}\text { Upstream } \\
N=259\end{array}$ & $\begin{array}{l}P \text { value } \\
\text { (no vs. up) }\end{array}$ & $\begin{array}{l}\text { Downstream } \\
N=391\end{array}$ & $\begin{array}{l}P \text { value } \\
\text { (no vs. down) }\end{array}$ \\
\hline \multicolumn{6}{|l|}{ On admission } \\
\hline ASA & $1,706 / 2,173(78.5 \%)$ & $166 / 234(70.9 \%)$ & $<0.01$ & $272 / 370(73.5 \%)$ & $<0.05$ \\
\hline Clopidogrel & $760 / 2,171(35.0 \%)$ & $86 / 235(36.6 \%)$ & ns & $104 / 369(28.2 \%)$ & $<0.05$ \\
\hline Ticlopidine & $67 / 2,171(3.1 \%)$ & $3 / 235(1.3 \%)$ & ns & $18 / 369(4.9 \%)$ & ns \\
\hline Vitamin $\mathrm{K}$ antagonist & $69 / 2,171(3.2 \%)$ & $6 / 234(2.6 \%)$ & ns & $8 / 369(2.2 \%)$ & ns \\
\hline \multicolumn{6}{|l|}{ Before or during PCI } \\
\hline ASA & $1,726 / 2,267(76.1 \%)$ & $216 / 257(84.0 \%)$ & $<0.01$ & $342 / 390(87.7 \%)$ & $<0.0001$ \\
\hline Clopidogrel overall & $1,806 / 2,267(79.7 \%)$ & $217(83.8 \%)$ & ns & $304(77.7 \%)$ & ns \\
\hline Clopidogrel loading dose upstream & $1,142 / 2,236(51.1 \%)$ & $138 / 254(54.3 \%)$ & ns & $183 / 377(48.5 \%)$ & ns \\
\hline Clopidogrel loading dose started in cathlab & $690 / 2,268(30.4 \%)$ & $72 / 258(27.9 \%)$ & ns & $103 / 390(26.4 \%)$ & $\mathrm{ns}$ \\
\hline Ticlopidine & $78 / 2,267(3.4 \%)$ & $6(2.3 \%)$ & ns & $21(5.4 \%)$ & ns \\
\hline Unfractionated heparin & $2,035 / 2,271(89.6 \%)$ & $169(65.3 \%)$ & $<0.0001$ & $333(85.2 \%)$ & 0.01 \\
\hline Low molecular weight heparin & $763 / 2,270(33.6 \%)$ & $156(60.2 \%)$ & $<0.0001$ & $180(46.0 \%)$ & $<0.0001$ \\
\hline \multicolumn{6}{|l|}{ At discharge } \\
\hline ASA & $2,128 / 2,186(97.3 \%)$ & $235 / 242(97.1 \%)$ & ns & $367 / 381(96.3 \%)$ & ns \\
\hline Clopidogrel & $1,980 / 2,185(90.6 \%)$ & $232 / 242(95.9 \%)$ & $<0.01$ & $341 / 381(89.5 \%)$ & ns \\
\hline Ticlopidine & $101 / 2,185(4.6 \%)$ & $6 / 242(2.5 \%)$ & ns & $22 / 381(5.8 \%)$ & ns \\
\hline Vitamin $\mathrm{K}$ antagonist & $61 / 2,180(2.8 \%)$ & $5 / 241(2.1 \%)$ & ns & $6 / 379(1.6 \%)$ & ns \\
\hline
\end{tabular}

utilization among patients with hemodynamic instability (cardiogenic shock or/and resuscitation). Upstream GPI was more often accompanied by the use of LMWH than UFH (Fig. 3).

Determinants for the downstream use of GPI

The multivariate analysis revealed the following independent determinants for the downstream use of GPI in decreasing order of importance (using odd ratios): Mediterranean region, no/slow flow, $>1$ segment treated, DES and type $\mathrm{C}$ lesion. Patients with acute segment occlusion tended to be more often treated with GPI, but the level of significancy was just missed. Renal insufficiency was negatively associated with downstream use (Fig. 4).

\section{Hospital complications}

In comparison to diabetics with no GPI therapy the incidence of hospital death was significantly higher in patients with upstream (4.6 vs. $1.7 \%, p=0.001)$ and similar in patients with downstream (1.8 vs. $1.7 \%, p=0.97)$ treatment (Fig. 5). After adjustment for confounding variables no significant differences in the risk for hospital death could be seen in the upstream (OR 1.54, 95\% CI 0.673.57 ) and downstream (OR $0.81,95 \%$ CI $0.31-2.11$ ) versus the no GPI group.

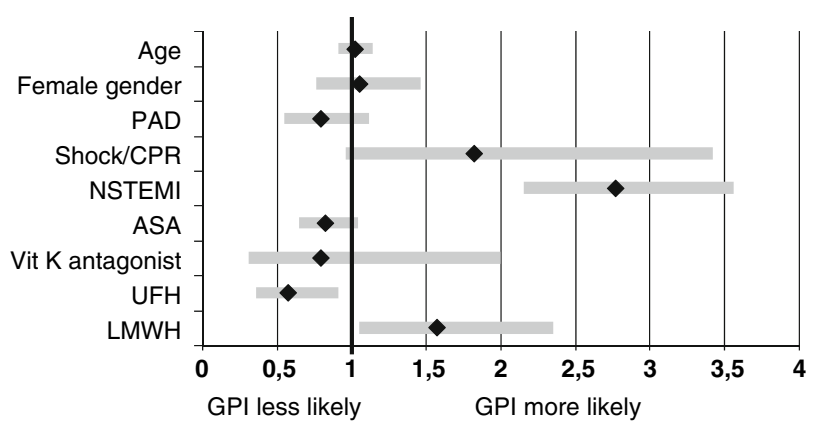

Fig. 3 Independent determinants for the upstream use of GP IIb/IIIa inhibitors

Compared to diabetics without GPI the incidence of non-fatal postprocedural myocardial infarction (8.1 vs. $1.1 \%, p<0.0001)$ and major bleedings (3.1 vs. $1.0 \%$, $p=0.008$ ) occurred more often among those treated with an upstream regime. In patients with downstream regime the rate of postprocedural myocardial infarction (3.6 vs. $1.1 \%, p=0.0001)$ and bleedings (2.6 vs. $1.0 \%, p=0.02$ ) was also increased. In the multiple regression analysis diabetics with upstream treatment (OR 4.12, 95\% CI 2.018.48) remained at elevated risk for myocardial infarction post PCI. There was also a tendency towards an increased risk for postprocedural myocardial infarction in the downstream group (OR 1.95, 95\% CI 0.85-4.46). No 


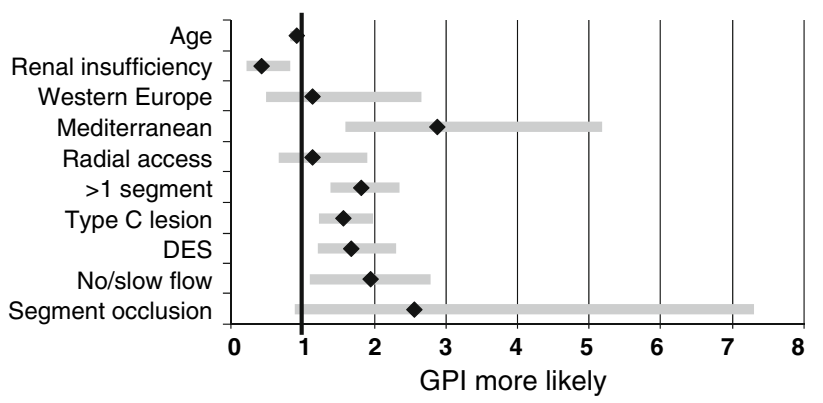

Fig. 4 Independent determinants for the downstream use of GP $\mathrm{IIb} / \mathrm{III}$ inhibitors

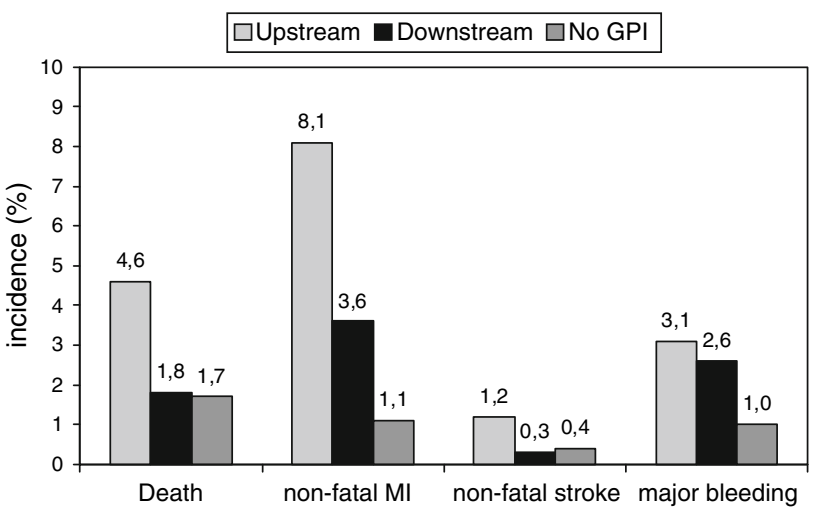

Fig. 5 Hospital complications in diabetics treated receiving upstream, downstream or no GP IIb/IIIa inhibitor treatment

significant difference in the occurrence of non-fatal strokes was observed (Fig. 5).

\section{Discussion}

This subgroup analysis of the EHS PCI Registry with nearly 3,000 diabetics undergoing PCI for NSTE-ACS investigated the use of GPI in clinical practice. The registry identified a low use of GPI despite the recommendation for its application in the current ESC guidelines. In particular, clinical stable diabetics with chronic renal insufficiency were less frequently treated. Patients with NSTEMI and hemodynamic instability were more likely to receive upstream, and those with more complex lesions downstream administration of GPI. After adjustment for confounding factors no significant differences in hospital mortality could be observed.

Roffi and colleagues demonstrated that there is a clear benefit of GPI among diabetics with NSTE-ACS. There is a pathophysiological plausibility to support this finding. Diabetics with ACS are at higher risk for major adverse events than non-diabetic patients. It has been hypothesized that hemostatic factors play an important role; altered platelet activation as well as impaired fibrinolysis have been found in diabetics $[10,11]$.

The most recent ESC guidelines for PCI and NSTEACS recommend the use of GPI in high risk patients with ACS, particularly in patients with diabetes undergoing PCI $[9,12]$. In previous observational studies a low use of GPI has already been documented [13]. In the 2005 Euro Heart Survey on coronary revascularization, which analyzed data from 2000/2001 only 32\% of the patients undergoing PCI for NSTE-ACS received GPI [14]. However, no difference was seen between patients with and without diabetes, which is in contrast to contemporary practice. In the EHS PCI Registry, diabetics with NSTE-ACS were less likely to receive GPI compared to their non-diabetic counterparts. In the USA, the use of GPI appears to be higher [15]. Results from the CRUSADE Quality Improvement Initiative revealed the use of GPI in over 50\% of the patients with NSTE-ACS undergoing coronary angiography within $48 \mathrm{~h}$ of presentation.

A multiple logistic regression analysis was performed to identify the reasons for and against GPI treatment in clinical practice. Clinical status had a major impact on the decision of the treating physician to use GPI upstream. Diabetics with hemodynamic instability, and NSTEMI were more likely to receive GPI upstream than downstream, however, the majority of patients with elevated troponins, cardiogenic shock and resuscitation did not actually receive GPI. On the contrary, chronic renal insufficiency made it less probable for the patient to be treated with GPI. It is well known that the use of GPI is associated with an increased risk for bleeding complications in patients with impaired renal function [16], however, the incidence of bleeding events can be minimized by weight-based heparin dosing, reduction of the GPI dose and early vascular access sheath removal following PCI [17-19]. In the end, the net clinical benefit might even be greater in patients with renal insufficiency despite the bleeding risk [20].

As expected, angiographic and procedural factors strongly influenced the downstream application of GPI. Diabetics undergoing complex interventions were more likely to receive GPI. Peri-procedural complications such as no/slow flow, and acute segment occlusion were independent predictors for administration of downstream GPI. Patients receiving DES were also more frequently treated with a downstream regime.

Furthermore, the strategy of the individual institution was one of the most meaningful determinants for the use of GPI, with large differences observed in the utilization of GPI between the participating centres. In some centres all patients, in others no patients received GPI. This is in line with findings from the Euro Heart Survey on coronary 
revascularization [14]. Large regional differences were also seen in our analysis; with the usage of GPI, in particular downstream, highest in Mediterranean countries.

Patients receiving GPI constitute a high risk group among diabetics with NSTE-ACS, and their risk for hospital death, postprocedural myocardial infarction and major bleeding is accordingly increased. This is mainly due to a strong selection bias for the use of GPI in patients with unstable presentation, and those undergoing complicated intervention. In the multiple regression analysis no significant differences in hospital mortality could be observed among the three patient cohorts. However, even after adjustment for confounding variables the risk for myocardial infarction post PCI is increased among patients receiving GPI, in particular in those with upstream treatment. This observation is in contrast to previous randomized controlled and observational studies favouring GPI [8, 21]. One possible explanation is the fact that GPI were more frequently used in high-risk scenarios and it may remain a substantial selection bias, which cannot be covered by the routine parameters in the multivariate analysis.

Despite the low use in clinical practice there is an ongoing debate about the proper role of GPI in the management of patients with NSTE-ACS today. As mentioned earlier dual antiplatelet therapy and stents were not routinely used at the time studies supporting the GPI use were performed. Studies with patients undergoing elective PCI after pretreatment with clopidogrel demonstrated little or no benefit of GPI [22,23]. New studies published after the finalization of the ESC PCI guidelines have provided additional conflicting data about the routine use of GPI in patients undergoing PCI for NSTE-ACS, particulary in the light of new antithrombotic treatment strategies.

In the ISAR-REACT 2 trial abciximab indeed reduced the risk of adverse events in patients with NSTE-ACS undergoing PCI notwithstanding clopidogrel pre-treatment and high stenting rate [24]. However, considering that prasugrel might be a stronger and more stable antiplatelet agent the role of GPI use in the setting of ACS will possibly be redefined [25]. In the ACUITY trial bivalirudin alone was associated with similar rates of ischemia and significantly lower rates of bleeding in comparison to GPI plus heparin [26]. In addition, the optimal timing for the initiation of treatment with GPI in patients with ACS is still unclear. In the recently published EARLY ACS trial the early use was not superior to the provisional use of eptifibatide after coronary angiography in patients with NSTE-ACS [27].

\section{Limitations}

As the nature of the study is exploratory, the findings should be interpreted cautiously. As stated above, individual interpretation of the clinical setting by the treating physicians cannot be reflected by the data collected in registries and therefore might contribute to a remaining selection bias which cannot adjust for even in thoughtful multivariate analysis.

\section{Summary}

In this analysis of the PCI-Registry of the Euro Heart Survey Programme a low use of GPI was identified among diabetics undergoing PCI for NSTE-ACS. The strategy of the individual institution was one of the most powerful determinants for the use of GPI. Patients were also more likely to receive GPI in a high risk scenario. Clinical instability was a strong determinant for an upstream, and complex lesions and interventions for a downstream application of GPI. Chronic renal failure was negatively associated with the use of GPI. After adjustment for confounding variables no significant differences in hospital mortality could be observed between the three groups, but a significantly higher rate of non-fatal myocardial infarction was seen post PCI among patients receiving GPI upstream. However, it may remain a substantial selection bias, which cannot be fully eliminated even by using a multivariate analysis.

Open Access This article is distributed under the terms of the Creative Commons Attribution Noncommercial License which permits any noncommercial use, distribution, and reproduction in any medium, provided the original author(s) and source are credited.

\section{References}

1. Lefkovits J, Plow EF, Topol EJ (1995) Platelet glycoprotein IIb/IIIa receptors in cardiovascular medicine. N Engl J Med 332:1553-1559

2. Said SM, Hahn J, Schleyer E, Müller M, Fiedler GM, Buerke M, Prondzinsky R (2007) Glycoprotein IIb/IIIa inhibitor-induced thrombocytopenia: diagnosis and treatment. Clin Res Cardiol 96:61-69

3. Boersma E, Akkerhuls KM, Théroux P, Califf RM, Topol EJ, Simoons ML (1999) Platelet glycoprotein IIb/IIIa inhibition in non-ST-elevation acute coronary syndromes: early benefit during medical treatment only, with additional protection during percutaneous coronary intervention. Circulation 100:2045-2048

4. Iijima R, Ndrepepa G, Mehilli J, Neumann FJ, Schulz S, ten Berg J, Bruskina O, Dotzer F, Dirschinger J, Berger PB, Schömig A, Kastrati A (2008) Troponin level and efficacy of abciximab in patients with acute coronary syndromes undergoing early intervention after clopidogrel pretreatment. Clin Res Cardiol 97:160168

5. Roffi M, Chew DP, Mukherjee D, Bhatt DL, White JA, Moliterno DJ, Heeschen C, Hamm CW, Robbins MA, Kleimann NS, Théroux P, White HD, Topol EJ (2002) Platelet glycoprotein IIb/IIIa inhibition in acute coronary syndromes. Gradient of benefit related to the revascularization strategy. Eur Heart J 23:1441-1448 
6. Granger CB, Califf RM, Young S, Candela R, Samaha J, Worley S, Kereiakes DJ, Topol EJ (1993) Outcome of patients with diabetes mellitus and acute myocardial infarction treated with thrombolytic agents. The Thrombolysis and Angioplasty in Myocardial Infarction (TAMI) Study Group. J Am Coll Cardiol 21:920-925

7. Malmberg K, Yusuf S, Gerstein HC, Brown J, Zhao F, Hunt D, Piegas L, Calvin J, Keltai M, Budaj A (2000) Impact of diabetes on long-term prognosis in patients with unstable angina and nonQ-wave myocardial infarction: results of the OASIS (Organization to Assess Strategies for Ischemic Syndromes) Registry. Circulation 102:1014-1019

8. Roffi M, Chew DP, Mukherjee D, Bhatt DL, White JA, Heeschen C, Hamm CW, Moliterno DJ, Califf RM, White HD, Kleiman NS, Théroux P, Topol EJ (2001) Platelet glycoprotein IIb/IIIa inhibitors reduce mortality in diabetic patients with non-STsegment-elevation acute coronary syndromes. Circulation 104:2767-2771

9. Silber S, Albertsson P, Avilés FF, Camici PG, Colombo A, Hamm CW, Jørgensen E, Marco J, Nordrehaug JE, Ruzyllo W, Urban P, Stone GW, Wijns W (2005) Guidelines for percutaneous coronary interventions. Eur Heart J 26:804-847

10. Shechter M, Merz CN, Paul-Labrador MJ, Kaul S (2000) Blood glucose and platelet-dependent thrombosis in patients with coronary artery disease. J Am Coll Cardiol 35:300-307

11. Auwerx J, Bouillion R, Collen D, Geboers J (1998) Tissue-type plasminogen activator antigen and plasminogen activator inhibitor in diabetes mellitus. Arteriosclerosis 47:68-72

12. Bassand JP, Hamm CW, Ardissino D, Boersma E, Budaj A, Fernández-Avilés F, Fox KAA, Hasdai D, Ohman EM, Wallentin L, Wijns W (2007) Guidelines for the diagnosis and treatment of non-ST-segment elevation acute coronary syndromes. Eur Heart J 28:1598-1660

13. Onuma Y, Kukreja N, Ramcharitar S, Hochadel M, Gitt A, Serruys $P$ (2009) Interventional treatment in diabetics in the era of drug-eluting stents and compliance to the ESC guidelines: lessons learned from the Euro Heart Survey Programme. EuroIntervention 4:578-587

14. Lenzen MJ, Boersma E, Bertrand ME, Maier W, Moris C, Piscione F, Sechtem U, Stahle E, Widimsky P, de Jaegere P, Scholte op Reimer WJ, Mercado N, Wijns W (2005) Management and outcome of patients with established coronary artery disease: the Euro Heart Survey on coronary revascularization. Eur Heart J 26:1169-1179

15. Bhatt DL, Roe MT, Peterson ED, Li Y, Chen AY, Harrington RA, Greenbaum AB, Berger PB, Cannon CP, Cohen DJ, Gibson CM, Saucedo JF, Kleinman NS, Hochman JS, Boden WE, Brindis RG, Peacock WF, Smith SC Jr, Pollack CV Jr, Gibler WB, Ohman EM (2004) Utilization of early invasive management strategies for high-risk patients with non-ST-segment elevation acute coronary syndromes: results from the CRUSADE Quality Improvement Initiative. JAMA 292:2096-2104

16. Berger PB, Best PJM, Topol EJ, White J, DiBattiste PM, Chan AW, Kristensen SD, Herrmann HC, Moliterno DJ (2005) The relation of renal function to ischemic and bleeding outcomes with 2 different glycoprotein IIb/IIIa inhibitors: the do Tirofiban and ReoPro Give Similar Efficacy Outcome (TARGET) trial. Am Heart J 149:869-875

17. Lincoff AM, Tcheng JE, Califf RM, Bass T, Popma JJ, Teirstein PS, Kleiman NS, Hattel LJ, Anderson HV, Ferguson JJ, Cabot
CF, Anderson KM, Berdan LG, Musco MH, Weisman HF, Topol EJ (1997) Standard versus low-dose weight-adjusted heparin in patients treated with the platelet glycoprotein IIb/IIIa receptor antibody fragment abciximab (c7E3 Fab) during percutaneous coronary revascularization. Am J Cardiol 79:286-291

18. The EPILOG Investigators (1997) Platelet glycoprotein IIb/IIIa receptor blockade and lowdose heparin during percutaneous coronary revascularization. N Engl J Med 336:1689-1696

19. Kirtane AJ, Piazza G, Murphy SA, Budiu D, Morrow DA, Cohen DJ, Peterson E, Lakkis N, Herrmann HC, Palabrica TM, Gibson CM (2006) Correlates of bleeding events among moderate- to high-risk patients undergoing percutaneous coronary intervention and treated with eptifibatide: observations from the PROTECTTIMI-30 trial. J Am Coll Cardiol 47:2374-2379

20. Freeman RV, Mehta RH, Al Badr W, Cooper JV, Kline-Rogers E, Eagle KA (2003) Influence of concurrent renal dysfunction on outcomes of patients with acute coronary syndromes and implications of the use of glycoprotein IIb/IIIa inhibitors. J Am Coll Cardiol 41:718-724

21. Dabbous OH, Anderson FA Jr, Gore JM, Eagle KA, Fox KA, Mehta RH, Goldberg RJ, Agnelli G, Steg PG (2008) Outcomes with the use of glycoprotein IIb/IIIa inhibitors in non-ST-segment elevation acute coronary syndromes. Heart 94:159-165

22. Kastrati A, Mehilli J, Schühlen H, Dirschinger J, Dotzer F, ten Berg JM, Neumann FJ, Bollwein H, Volmer C, Gawaz M, Berger PB, Schömig A (2004) A clinical trial of abciximab in elective percutaneous coronary intervention after pretreatment with clopidogrel. N Engl J Med 350:232-238

23. Mehilli J, Kastrati A, Schühlen H, Dibra A, Dotzer F, von Beckerath N, Bollwein H, Pache J, Dirschinger J, Berger PP, Schömig A (2004) Randomized clinical trial of abciximab in diabetic patients undergoing elective percutaneous coronary interventions after treatment with a high loading dose of clopidogrel. Circulation 110:3627-3635

24. Kastrati A, Mehilli J, Neumann FJ, Dotzer F, ten Berg J, Bollwein H, Graf I, Ibrahim M, Pache J, Seyfarth M, Schühlen H, Dirschinger J, Berger PB, Schömig A (2006) Abciximab in patients with acute coronary syndromes undergoing percutaneous coronary intervention after clopidogrel pre-treatment. JAMA 295:1531-1538

25. Wiviott SD, Braunwald E, Angiolillo DJ, Meisel S, Dalby AJ, Verheugt FWA, Goodman SG, Corbalan R, Purdy DA, Murphy SA, McCabe CH, Antman EM (2008) Greater clinical benefit of more intensive oral antiplatelet therapy with prasugrel in patients with diabetes mellitus in the trial to assess improvement in therapeutic outcomes by optimising platelet inhibition with prasugrel-thrombolysis in myocardial infarction 38. Circulation 118:1626-1636

26. Stone GW, McLaurin BT, Cox DA, Bertrand ME, Lincoff AM, Moses JW, White HD, Pocock SJ, Ware JH, Feit F, Colombo A, Aylward P, Cequier AR, Darius H, Desmet W, Ebrahimi R, Hamon M, Rasmussen LH, Rupprecht HJ, Hoekstra JW, Mehran R, Ohman EM (2006) Bivalirudin for patients with acute coronary syndromes. N Engl J Med 355:2203-2216

27. Giugliano RP, White JA, Bode C, Armstrong PW, Montalescot G, Lewis BS, vant Hof A, Berdan LG, Lee KL, Storny JT, Hildermann S, Veltri E, Van de Werf F, Braunwald E, Harrington RA, Califf RM, Newby LK (2009) Early versus delayed, provisional eptifibatide in acute coronary syndromes. N Engl J Med 360:2176-2190 